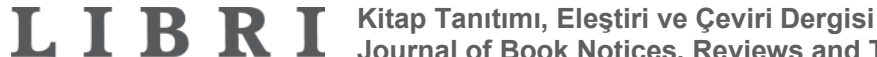 \\ ww w. libridergi.org Journal of Book Notices, Reviews and Translations
}

Volume II (2016)

\section{Plutarkhos, Moralia: Şans Üzerine}

\author{
Plutarkhos, Moralia: De Fortuna
}

\section{Çeviren: Selda YENi}

open access journals

Libri: Kitap Tanıtımı, Eleştiri ve Çeviri Dergisi'nde bulunan içeriklerin tümü kullanıcılara açık, serbestçe/ücretsiz "açık erişimli” bir dergidir. Kullanıcılar, yayıncıdan ve yazar(lar)dan izin almaksızın, dergideki kitap tanıtımlarını, eleştirileri ve çevirileri tam metin olarak okuyabilir, indirebilir, dağıtabilir, çıktısını alabilir ve kaynak göstererek bağlantı verebilir.

Libri, uluslararası hakemli elektronik (online) bir dergi olup değerlendirme süreci biten kitap tanıtımları, eleştiriler ve çeviriler derginin web sitesinde (libridergi.org) yıl boyunca ilgili sayının içinde (Volume II: Ocak-Aralık 2016) yayımlanır. Aralık ayı sonunda ilgili yıla ait sayı tamamlanır.

Dergide yayımlanan eserlerin sorumluluğu yazarlarına aittir.

Atıf Düzeni: Plutarkhos, Moralia: Şans Üzerine. Çev. S. Yeni. Libri II (2016) 366-378. DOI: $10.20480 /$ lbr.2016020

Geliş Tarihi: 04.05.2016 | Kabul Tarihi: 10.06.2016

Elektronik Yayın Tarihi: 29.07.2016

Editörya: Phaselis Research Project

www.libridergi.org 


\section{ПIEPI T'YXH $\Sigma$}

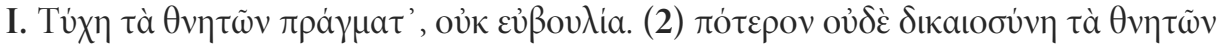

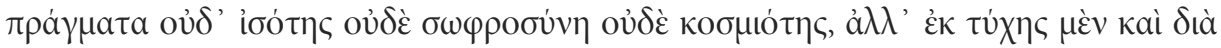

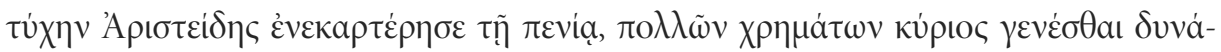

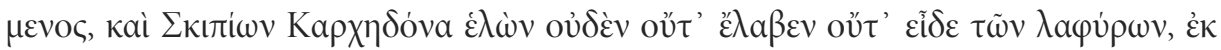

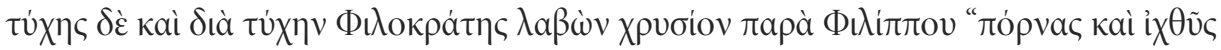

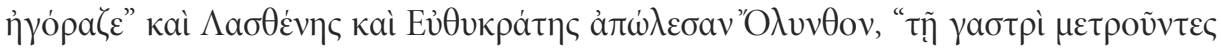

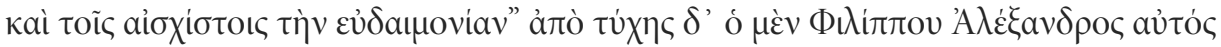

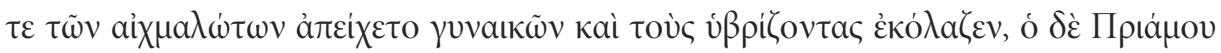

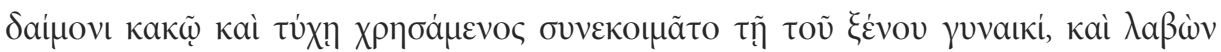

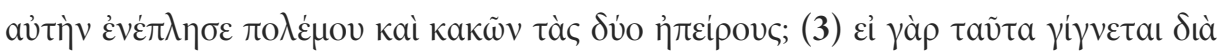

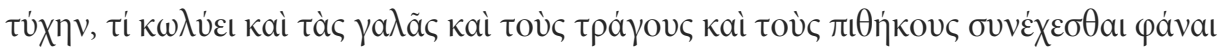

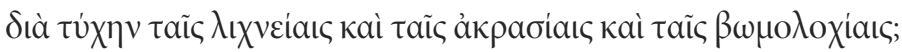

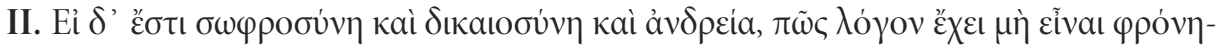

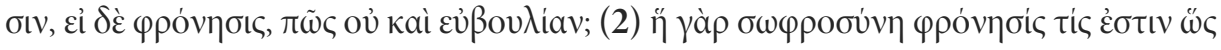

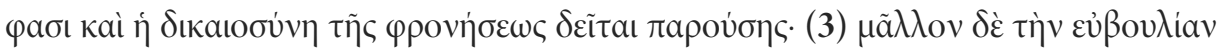

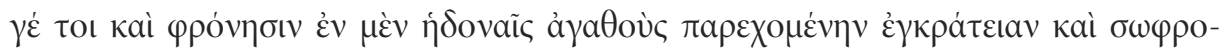

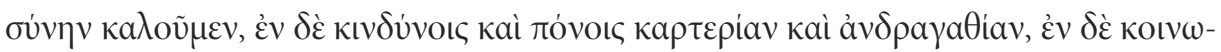

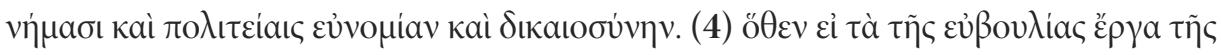

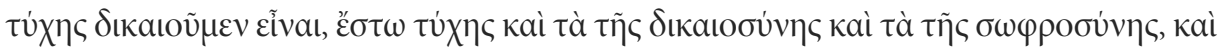

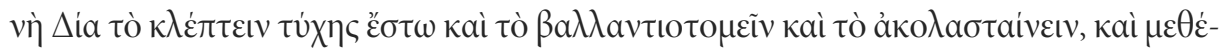

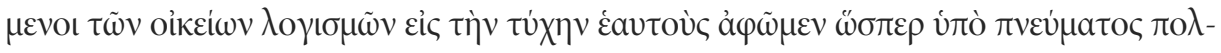

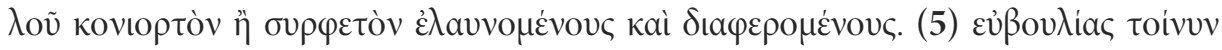




\section{ŞANS ÜZERINE}

Çeviren Selda YENi*

I. Fanilerin işlerini sağduyu değil, şans yönetir ${ }^{1}$. (2) Ne adalet, ne eşitlik, ne ölçülülük ne de aklıselimlik fanilerin işlerini yönetir mi? Nitekim Aristeides'in büyük bir servet sahibi olmaya muktedirken, yoksulluğunu sürdürmesi ${ }^{2}$ ve Scipio'nun Kartaca'yı ele geçirdiğinde ganimetleri ne görüp ne de alması şans sonucunda veya şans sayesinde midir? Philokrates'in ${ }^{3}$ Philippos'tan altın aldığında "fahişeler ve balıklar satın alması"; Lasthenes ve Euthykrates'in "mutluluğu yeme-içme ve utanç verici işlerle ölçerek" Olynthos'u kaybetmeleri ${ }^{4}$ şans sonucunda ve şans sayesinde midir? Philippos'un oğlu Aleksandros'un bizzat kendisi hem esir kadınlara yaklaşmaması hem de taciz edenleri cezalandırma$\mathrm{sI}^{5}$, Priamos oğlu (Aleksandros'un) ise tanrısal bir esinle ve şansla davranarak yabancı birinin eşiyle yatması ve onu alarak iki toprağı da savaş ve kötülüklerle doldurması şanstan ötürü müdür? (3) Gerçekten de eğer tüm bunlar şanstan dolayı oluyorsa, gelinciklerin, keçilerin ve maymunların şans eseri açgözlülük, şehvet ve maskaralılıklarla birarada tutulmuş olduklarını söylemeye ne engel olur?

II. Eğer aklıselimlik, adalet ve mertlik varsa, aklın olmadığı nasıl söylenir? Eğer akıl varsa, sağgörü de nasıl yoktur? (2) Zira söyledikleri gibi aklıselimlik bir çeşit akıldır ve adalet aklın olmasına ihtiyaç duyar. (3) Daha doğrusu sağgörü ve iyi şeylere yönlendiren aklı, sevinçliyken irade ve ölçülülük; tehlikeler ve zorluklarda sebat ve cesaret; sosyal ve politik yaşamda ise iyi düzen ve adalet olarak adlandırırız. (4) Bu nedenle, eğer sağgörü işlerinin şanstan olduğunu kabul edersek, adalet işleri ve akıl işleri de şanstan ötürü olsun ve Zeus aşkına! O zaman çalmak, para keselerini kesmek ve ahlaksız olmak da şanstan dolayı olsun ve sert rüzgarlar altındaki toz bulutu ve çerçöp gibi sürüklenip taşınanlar olarak yerleşmiş mantıkları terkedip kendimizi şansa bırakalım! (5) Bu nedenle, sağgörü

* MA., Akdeniz Üniversitesi, Edebiyat Fakültesi, Eskiçağ Dilleri ve Kültürleri Bölümü, Antalya. selda.yeni@gmail.com 


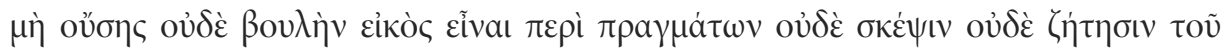

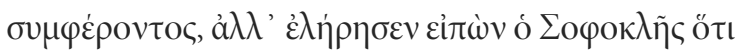

$\pi \tilde{a} v$ tò

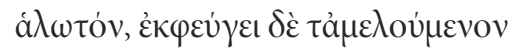

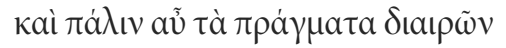

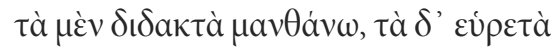

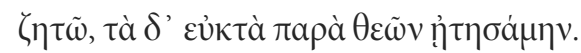

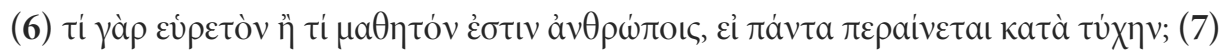

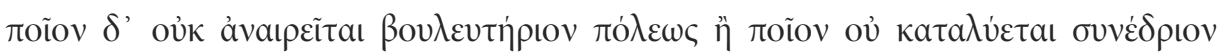

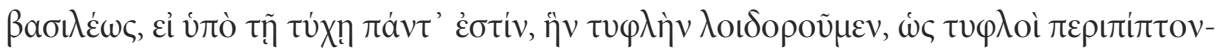

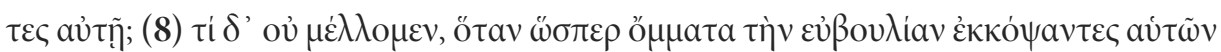

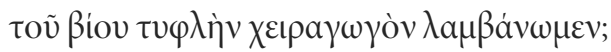

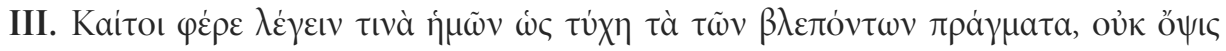

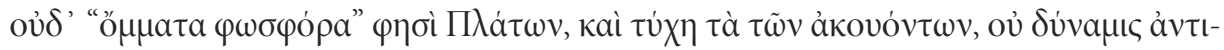

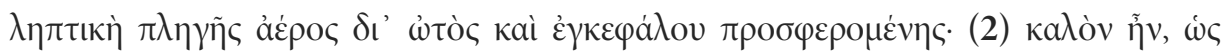

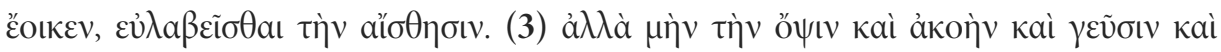

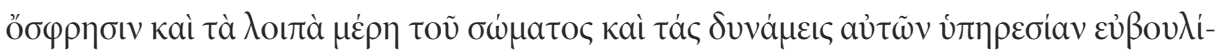

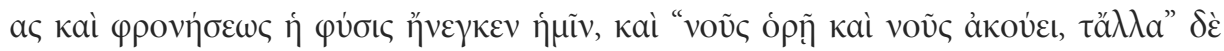

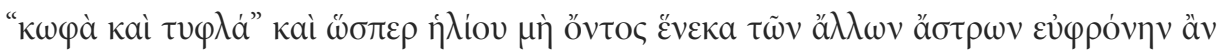

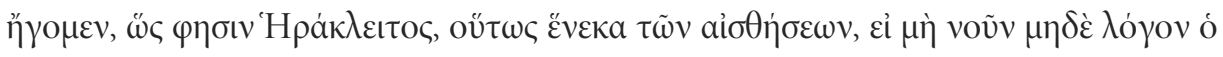

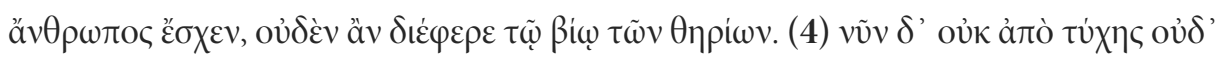

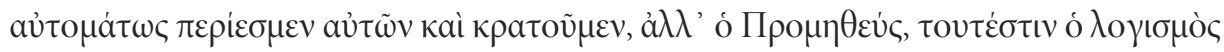
aítıৎ

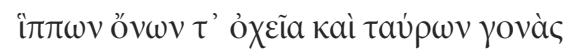

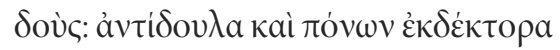

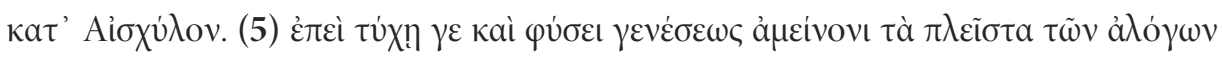

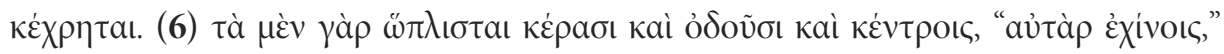

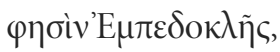

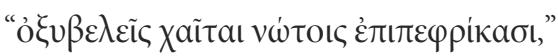

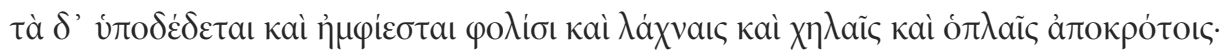

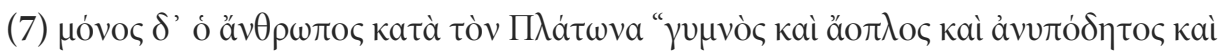

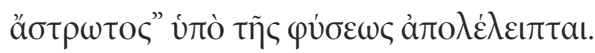


olmasaydı, işler hakkında ne kararın ne düşüncenin ne de yararı dokunacak bir şeyin araştırmasının olması olası olurdu. Nitekim Sophokles şu sözü söyleyerek boş konuşmuştur: "Bütün istenilen şey elde edilebilir, ihmal edilen ise kaçar" ${ }^{6}$. Başka bir seferinde yeniden işleri ayırarak şöyle söylemiştir: "öğretilenleri öğrenirim, keşfedilebilenleri araştırıım, tanrılar nezdinde istenilen şeyleri diledim" ${ }^{7}$. (6) Zira insanlar için hangi keşif ya da hangi öğreti şanstan dolayı başarılmıştır? (7) Eğer herşey şansa bağı ılsa, kentin bouleuterion'u nasıl yıkılmaz ya da kraIın meclisi nasıl yok olmaz? Tıpkı körler gibi rastladığımız (başımıza gelen) körlüğü kötülemez miyiz ${ }^{8}$ ? (8) Gözlerimiz gibi sağgörümüzü kesip attığımızda, hayatımıza körlüğü rehber olarak aldığımızda, nasıl ayırt ederiz (görürüz)?

III. Dahası içimizden birinin görme eylemini Platon'un söylediği gibi görme ve "Işık taşıyan gözler" değil de şans olduğunu, işitme eyleminin de kulak ve beyin vasıtasıyla aktarılan hava titreşiminin algısal gücü ${ }^{10}$ değil de yine şans olduğunu söylediğini varsayalım. (2) Görünüşe göre, algıya karşı dikkatli olmak iyi bir şeydir. (3) Ancak doğa bize görmeyi, duymayı, tatmayı, koklamayı, bedenin geri kalan kısımlarını ve bunların güçlerini sağduyu ve zekâya hizmet için getirdi. "Akıl görür ve akıl duyar, geri kalan her şey sağır ve kördür" ${ }^{11}$, Herakleitos'un dediği gibi, mesela güneş olmasa diğer yıldızlara rağmen bize gece olur$d^{12}$. Böylece hislere rağmen, eğer insan akla ve mantığa sahip olmasaydı, yaşayış bakımından vahşi hayvanlardan bir farkı olmazdı. (4) Oysa ne şanstan ötürü ne de kazayla onlardan daha üstünüz ve onları yönetiriz. Bunun sebebi Aiskhylos'a göre, atların ve eşeklerin yavrularını ve boğaların soylarını köleler yerine ve görevleri üstleniciler olarak (bize) veren Prometheus, yani düşünce gücüdür ${ }^{13}$. (5) Kuşkusuz, şans ve doğuştan gelen doğal durumdan ötürü hayvanların pek çoğu (insanlardan) daha faydalı özelliklere sahip olmuşlardır. (6) Zira bazıları boynuz, diş ve iğnelerle donatılmışlar, "ancak kirpiler", Empedokles'in dediğine göre, "sırtlarında dikenlerini kabartırlar" ${ }^{14}$; bazıları ise pullar, yünler, pençeler ve sert toynaklarla sarılmışlar ve örtülmüşlerdir. (7) Sadece insan, Platon'a göre, doğa tarafından "çıplak, korunmasız, yalınayak ve örtüsüz" bırakılmıştır ${ }^{15}$. 


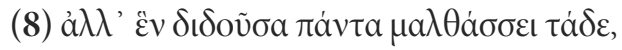

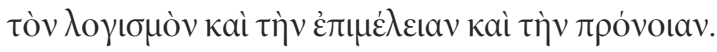

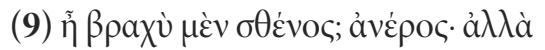

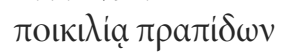

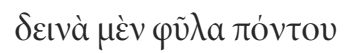

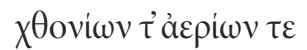

$\delta \dot{\mu} \mu v \alpha \tau a \iota ß o v \lambda \varepsilon \dot{\mu} \mu \alpha \tau \alpha$.

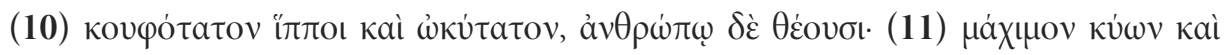

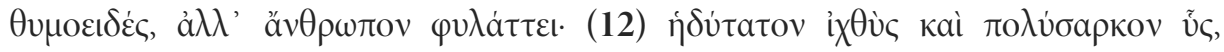

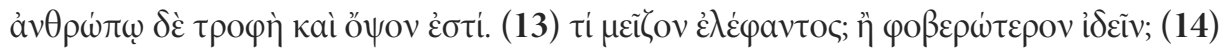

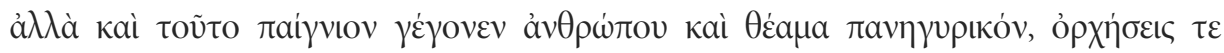

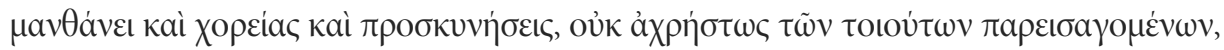

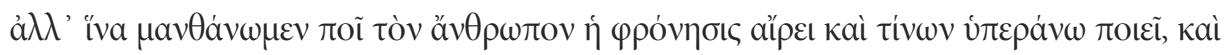

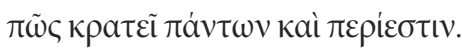

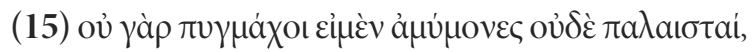

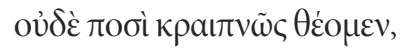

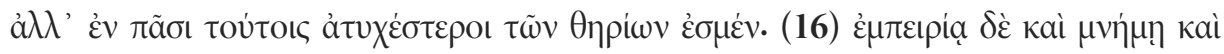

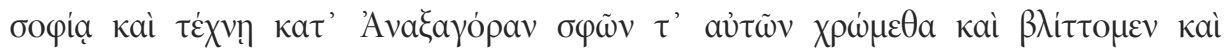

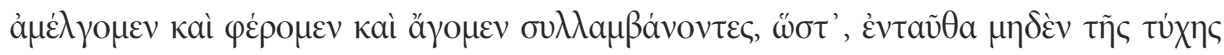

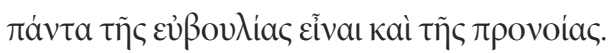

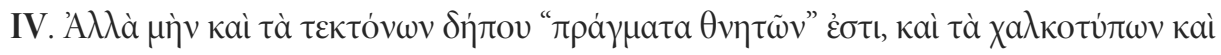

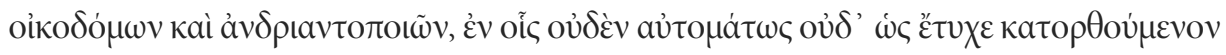

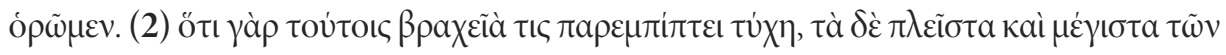

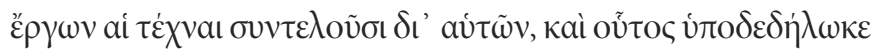

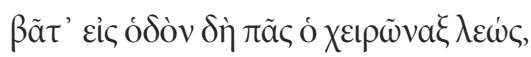

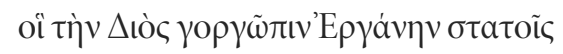

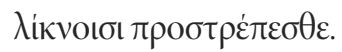

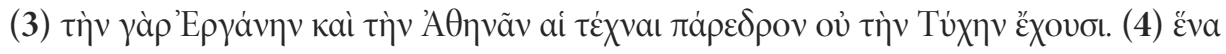

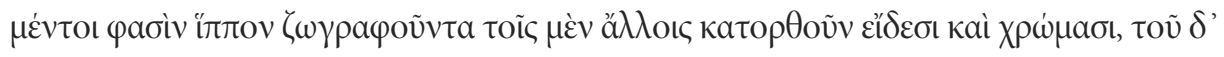

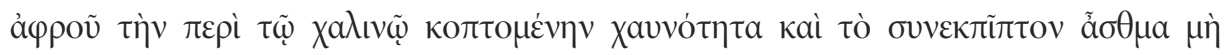

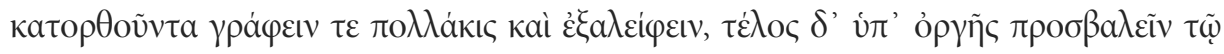

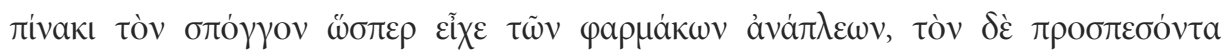

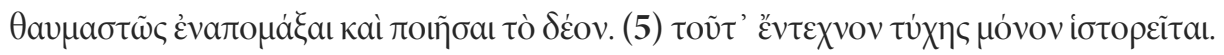


(8) Ancak, (doğa) tek bir şey -düşünce kabiliyeti, dikkati ve öngörüyü- vererek tüm bunları yatıştırmıştır. (9) Gerçekten insanın kuvveti azdır, ancak aklının çok yönlülüğü ile denizin, karanın ve göğün güçlü ırklarına ve amaçlarına egemen oldu. (10) En çevik ve çabuk hayvan olan atlar da insan için koşarlar. (11) En kavgacı ve cesur hayvan olan köpek yine insanı korur. (12) En hoş hayvan olan balık ve en şişman hayvan olan domuz insanın yiyeceği ve eti olur. (13) Filden daha büyük ya da daha korkutucu görülen ne vardır? (14) Ancak bu hayvan insanın oyuncağı haline gelmiştir ve festivalde gösteri objesi olmuştur, poz vermeyi, dans etmeyi ve reveransları öğrenmiştir. Böyle şeylerin sunulması boş yere değildir, ancak aklın insanı nereye yükselttiğini ve nelerden üstün kıldığını ve nasıl her şeyden güçlü olduğunu ve üstün geldiğini öğrenmemiz içindir. (15) Ancak ne mükemmel boksörleriz ne de güreşçileriz, ayaklarımızla (yaya olarak) süratli bir şekilde de koşmayız ${ }^{16}$, zira tüm bunlarda hayvanlardan daha şanssızız. (16) Deneyim, hafıza, bilgelik ve yeteneğimizle, Anaksagoras'a göre ${ }^{17}$, onlara ait şeylerden faydalanırız, bal alırız, süt sağarız, taşırız ve el koyarak sevk ederiz, öyle ki burada hiçbir şey şanstan değildir, her şey sağgörü ve öngörüdendir.

IV. Ancak şüphesiz marangozların işleri, bakırcıların, mimarların ve heykeltıraşların işleri "fanilerin işleridir", bunların ne kendiliğinden ne de şans eseri tamamlandığını görürüz. Zira bu işlerde şansın az etkisi vardır ${ }^{18}$, işlerin çoğunu ve büyük bir kısmını bu kişilerin ustalıkları (sanatları) başarır. (2) Bu da (şiir) anlatır: Yola çıkıyordunuz siz bütün zanaatkârlar, adak sunmak için hazırlanmış kutsal sepetlerle Zeus'un haşin gözlü kızı Ergane'ye ${ }^{19}$ dua ediyordunuz ${ }^{20}$. (3) Zira sanatların yanında şans değil, Athena Ergane vardır. (4) Ancak derler ki ressamın biri ${ }^{21}$ at resmederken form ve renkleri bakımından tüm geriye kalan şeylerde başarılı olmuştur. Atın dizgininin etrafında ortaya çıkan öfkeli tavrını ve nefesini resmederken köpüğün formunu ve şeklini başarılı bir şekilde veremediği için pek çok kez çizip silmiştir. Sonunda süngeri boyaları bulaştıracak kadar öfkeyle resme çarpınca oluşan görünüm fevkalade bir izlenim (ifade) almış ve arzu ettiğini yapmıştır. (5) Şans eseri yetenek olarak sadece bu anlatılır. 


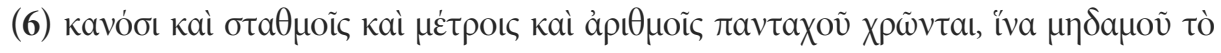

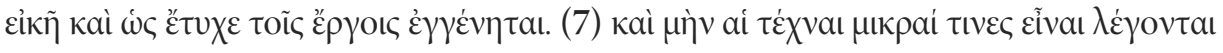

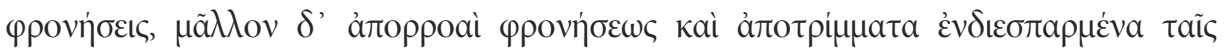

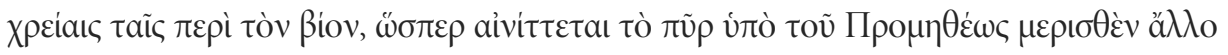

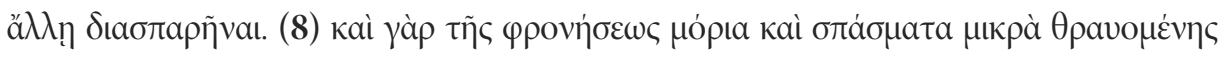

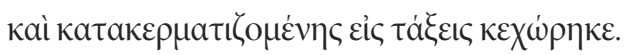

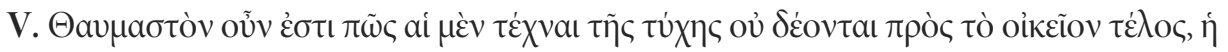

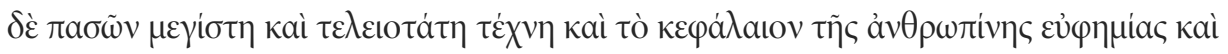

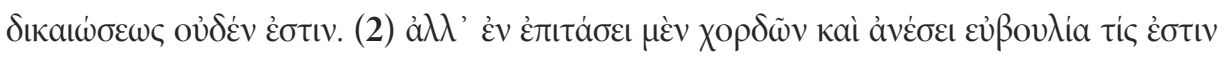

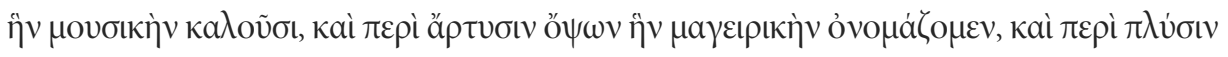

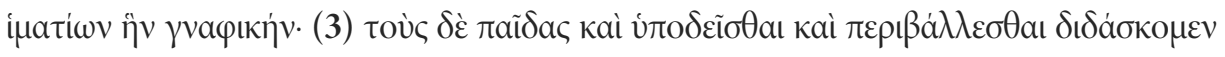

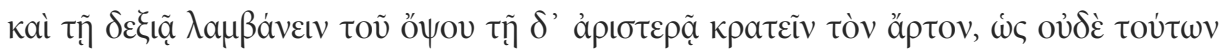

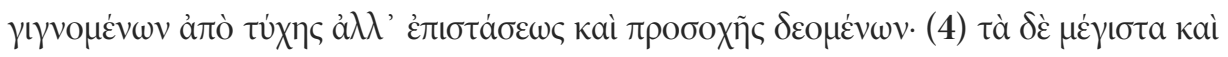

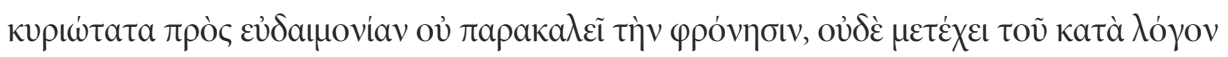

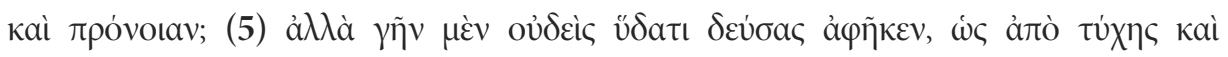

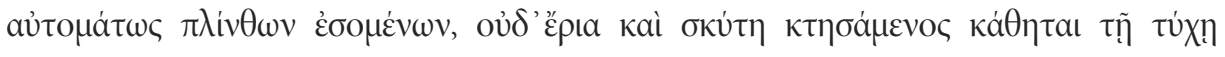

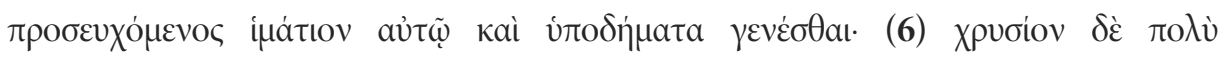

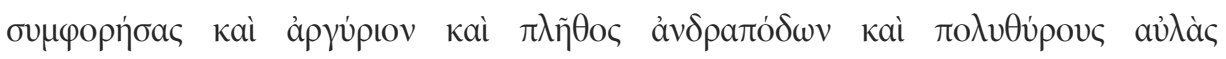

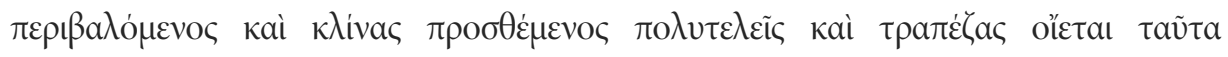

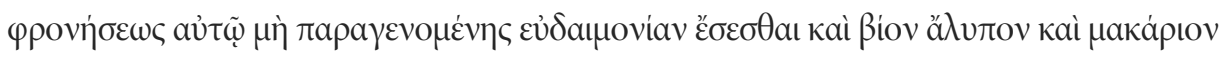

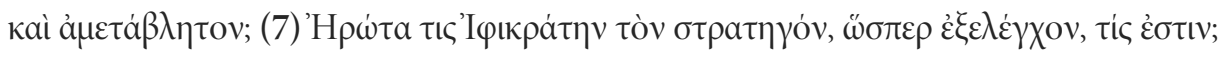

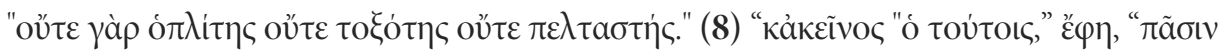

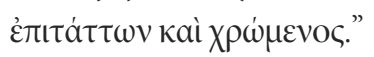

\section{VI}

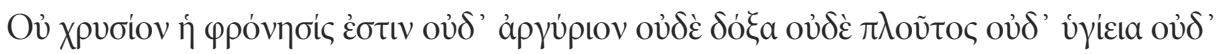

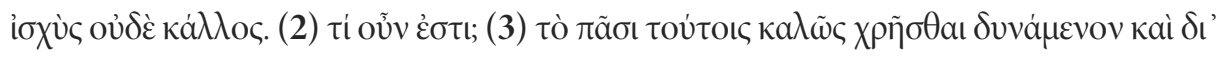

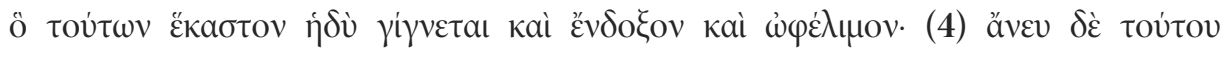

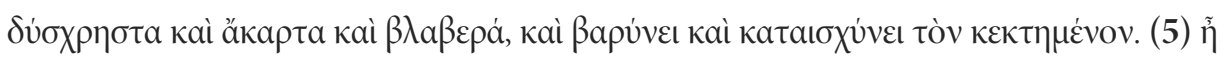

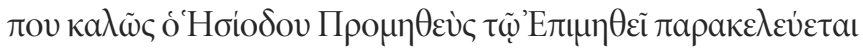

$\mu \eta \grave{\pi} \pi \mathrm{\tau} \varepsilon \delta \tilde{\omega} \rho \alpha$

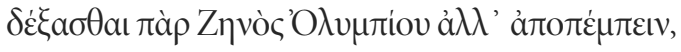


(6) Kurallardan, ağırlıklardan, ölçülerden ve sayılardan her yerde yararlanırlar, hiçbir yerde tesadüfen işler şans eseri ortaya çıkmaz. (7) Tıpkı ateşin Prometheus tarafından dağıtılarak her yana yayıldığının üstü kapalı söylendiği gibi, sanatların bir çeşit küçük fikirler oldukları, daha doğrusu aklın dışa vurumları ve hayata ilişkin ihtiyaç duyulanlar vesilesiyle yayılarak ortaya çıkan şeyler oldukları söylenir. (8) Zira zeka kırıntıları parçalanıp bölünerek yerlere yayıldı.

V. Uygun bir başarı için şansa ihtiyaç duymayan sanatlar nasıl da olağan üstüdür, herşeyin en harikası ve mükemmeli olan sanat ve insana ait onur ve itibarın toplamı da şanstan ötürü değildir. (2) Ancak tellerin gerilmesi ve gevşetilmesiyle oluşan müzik olarak adlandırdığınız şey ve ayrıca aşçılık olarak adlandırdığımız yemekleri tatlandırma olayı ve dinkleme (keçeleştirme işlemi) olarak adlandırdığımız giysileri yıkama işi bir çeşit sağgörüdür. (3) Çocuklarımıza ayakkabı ve giysi giyinmeyi ve eti sağ elle almayı, ekmeği ise solla tutmayı öğretiriz, öyle ki bunların hiç biri şanstan ötürü olmaz, ancak özen ve dikkat gerektirirler. (4) Mutluluk için çok önemli ve esaslı şeyleri zeki olmak için anmayız, mutluluk mantık ve öngörü uyarınca olan bir şeyin parçası değil midir? (5) Ancak şanstan ötürü ya da kendiliğinden tuğlalar oluşacak diye hiç kimse toprağı suyla ıslatıp bırakmadı, yünleri ve derileri elde edip kendisine giysi ve sandalet olması için şansa dua ederek oturmadı. (6) Biri pek çok altın, gümüş ve çok sayıda köleyi bir araya toplayıp çok kapılı avlularla çevirince ve içerisine pahalı kline ve masalar koyduğunda kendisinde akıl olmadan bunların mutluluk ve acısız, keyifli ve güvenli bir hayat sağlayacağını hayal eder mi? (7) Biri komutan Iphikrates'e suçlarcasına "kimsin?" diye sordu, "zira ne ağır silahlı ne okçu ne de hafif zırhlısı" . (8) O ise "bunların hepsine emreden ve hepsini kullanan kişiyim" dedi.

VI. Akıl ne altın ne gümüş ne ün ne zenginlik ne sağılık ne güç ne de güzelliktir. (2) O halde nedir? (3) Tüm bunları iyi bir şekilde kullanabilen bir şeydir ve onun sayesinde bunların her biri hoş, dikkate değer ve yararlı olur. (4) O olmadan (bunlar) yararsız, başarısız ve zararlı olur ve sahip olan kimseye sıkıntı verir ve onu rezil eder. (5) Hesiodos'un eserinde 22 Prometheus Epimetheus'a Olymposlu Zeus tarafından gelen hediyeleri asla kabul etmemesini; 


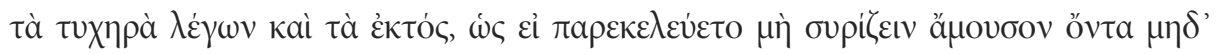

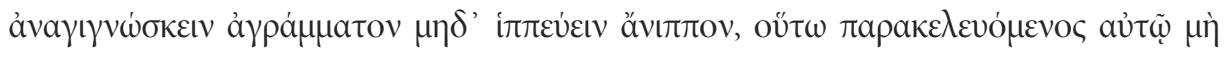

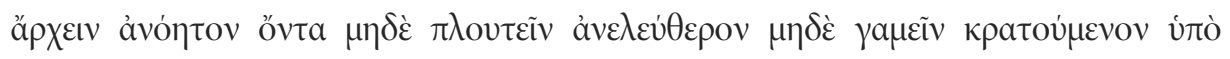

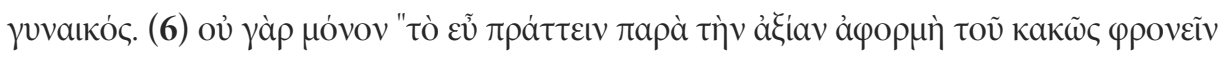

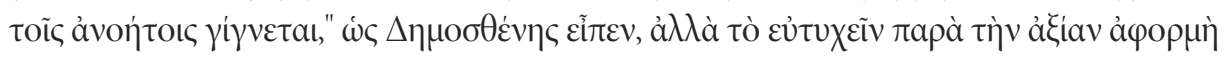

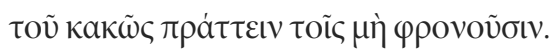


aksine şanslı şeyleri ve haricindeki şeyleri reddetmesini söyleyerek iyi bir tavsiyede bulunur. Biri müzikten habersizse flüt çalmamasını, okuma yazması yoksa okumamasını, atı kullanamaz durumdaysa ata binmemesini tavsiye eder; ayrıca akılsızsa kamu görevinde bulunmamasını, cimriyse zengin olmamasını, kadın tarafından yönetiliyorsa evlenmemesini tavsiye eder. (6) Zira sadece Demosthenes'in "haksız yere başarılı olma aklı başında olmayanların başını döndürür" dediği ${ }^{23}$ gibi değildir, aynı zamanda haksız yere şanslı olmak da aklı başında olmayanlara kötülük yaptırır. 


\section{Notlar}

Cic. Tusc. V. 9. 25; Nauck 1889, 782-783 no. 2.

Plut. Arist. 25.

Dem. Or. XIX. 8.

Dem. Or. XVIII. 48.

Plut. Alex. XXI.

Soph. Oid. T. 110.

Nauck 1889, 309 no. 759.

Kock 1888, 121 no. 417.

9 Plat. Tim. 45b.

10 Plat. Tim. 67b.

11 Plut. de Alex. 336b; de Soll. 961a; Diels 1912, 123.

12 Diels 1912, 97; bu ifadenin farklı bir versiyonu Plut. Aquane 957a'da yer almaktadır.

13 Nauck 1889, 65 no. 194.

14 Diels 1912, 252.

15 Plat. Prot. 321c.

16 Hom. Od. VIII. 246.

17 Diels 1912, 409.

18 Diog. Laert. X. 144.

19 Ergane işçilerin ve zanaatkârların tanrıçası Athena'nın epithetidir. Santoro 1973, 94 s.v.

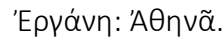

20 Nauck 1889, 309-310 no. 760.

21 Bu ressam Plinius'a (Plin. Nat. XXXV. 36) göre Nealkes'tir; Dion Khrysostomos'a (Dion Chrys. LXIII. 4) göre Apelles'tir; Valerius Maximus (Val. Max. VIII. 11. 7) ise sadece "ünlü bir ressam" demiştir.

22 Hes. Erg. 86.

23 Dem. Olynth. I. 23. 


\section{BIBLLIYOGRAFYA}

\section{Antik Kaynaklar}

Cic. Tusc.

Dem. Olynth.

Dem. Or.

Diog. Laert.

Dion Chrys.

Hes. Erg.

Hom. Od.

Plat. Prot.

Plat. Tim.

Plin. Nat.

Plut. Alex.
(= Marcus Tullius Cicero, Tusculanae Disputatione) Kullanılan Metin ve Çeviri: Cicero, Tusculan Disputations. Trans. J. E. King. London 1927 (Loeb Classical Library).

(= Demosthenes, Olynthiakos)

Kullanılan Metin ve Çeviri: Orations, vol. I. Trans. J. H. Vince. London 1930 (Loeb Classical Library).

(= Demosthenes, Orationes)

Kullanılan Metin ve Çeviri: Demosthenes, Orations 1819 De Corona, De Falsa Legatione. Trans. C. A. Vince J. H. Vince. London 1926 (Loeb Classical Library).

(= Diogenes Laertios, Epikyros)

Kullanılan Metin ve Çeviri: Diogenes Laertius, Lives of Eminent Philosophers Books 6-10. Trans. R. D. Hicks. London 1925 (Loeb Classical Library).

(= Dion Khrysostomos, Orationes)

Kullanılan Metin ve Çeviri: Dio Chrysostom, Discourses 61-80. Trans. H. L. Crosby. London 1951 (Loeb Classical Library).

(= Hesiodos, Erga kai Hemerai)

Kullanılan Metin ve Çeviri: Hesiod, Works and Days. Trans. H. G. Evelyn-White. London 1914.

(= Homeros, Odysseia)

Kullanılan Metin ve Çeviri: Homeros, Odysseia. Trans. A. Erhat - A. Kadir. İstanbul $2013^{27}$.

(= Platon, Protagoras)

Kullanılan Metin ve Çeviri: Plato, Plato in Twelve Volumes, vol. III. Trans. W. R. M. Lamb. London 1967.

(= Platon, Timaios)

Kullanılan Metin ve Çeviri: Plato, Timaeus, Critias, Cleitophon, Menexenus, Epistles. Trans. R. G. Bury. London 1929 (Loeb Classical Library).

(= Plinius, Naturalis Historia)

Kullanılan Metin ve Çeviri: Pliny, Natural History. Trans.

H. Rackham. London 1855 (Loeb Classical Library).

(= Plutarkhos, Aleksandros)

Kullanılan Metin ve Çeviri: Plutarch, Lives, Demosthe- 
Plut. Aquane

Plut. Arist.

Plut. de Alex.

Plut. de Soll.

Soph. Oid. T.

Val. Max.

\section{Modern Literatür}

Diels 1912

Kock 1888

Nauck 1889

Santoro 1973 nes and Cicero, Alexander and Caesar. Trans. B. Perrin. London 1919 (Loeb Classical Library). (= Plutarkhos, Aquane An Ignis Sit Utilior) Kullanılan Metin ve Çeviri: Plutarch, Moralia, vol. XII. Trans. H. Cherniss - W. C. Helmbold. London 1957 (Loeb Classical Library).

(= Plutarkhos, Aristides)

Kullanılan Metin ve Çeviri: Plutarch's Lives. Themistocles and Camillus; Aristides and Cato Major; Cimon and Lucullus. Trans. B. Perrin. London 1914 (Loeb Classical Library).

(= Plutarkhos, De Alexandri Magni Fortuna aut Virtute) Kullanılan Metin ve Çeviri: Plutarch, Moralia, vol. IV. Trans. F. C. Babbitt. London 1936 (Loeb Classical Library).

(= Plutarkhos, De Sollertia Animalium)

Kullanılan Metin ve Çeviri: Plutarch, Moralia, vol. XII. Trans. H. Cherniss - W. C. Helmbold. London 1957 (Loeb Classical Library).

(= Sophokles, Oidipous Tyrannos)

Kullanılan Metin ve Çeviri: The Oedipus Tyrannus of Sophocles. Trans. R. Jebb. Cambridge 1887.

(= Valerius Maximus, Factorum et Dictorum Memorabilium)

Kullanılan Metin ve Çeviri: Valerius Maximus, Memorable Doings and Sayings, Books 6-9. Trans. S. Bailey. London 2000 (Loeb Classical Library).

H. Diels, Die Fragmente der Vorsokratiker, Band I. Berlin 1912.

T. Kock, Comicorum Atticorum Fragmenta III. Leipzig 1888.

A. Nauck, Tragicorum Graecorum Fragmenta. Leipzig 1889.

M. Santoro, Epitheta Deorum in Asia Graeca Cultorum Ex Auctoribus Graecis et Latinis. Milano 1973. 